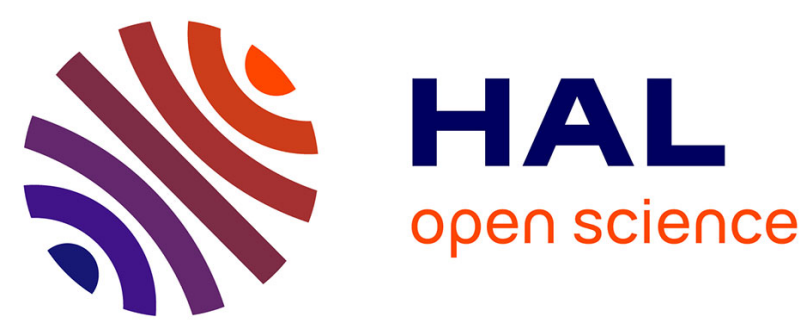

\title{
DABGPM: A Double Auction Bayesian Game-based Pricing Model in Cloud Market
}

Shifeng Shang, Jinlei Jiang, Yongwei Wu, Zhenchun Huang, Guangwen Yang, Weimin Zheng

\section{- To cite this version:}

Shifeng Shang, Jinlei Jiang, Yongwei Wu, Zhenchun Huang, Guangwen Yang, et al.. DABGPM: A Double Auction Bayesian Game-based Pricing Model in Cloud Market. IFIP International Conference on Network and Parallel Computing (NPC), Sep 2010, Zhengzhou, China. pp.155-164, 10.1007/9783-642-15672-4_14. hal-01054981

\section{HAL Id: hal-01054981 \\ https://inria.hal.science/hal-01054981}

Submitted on 11 Aug 2014

HAL is a multi-disciplinary open access archive for the deposit and dissemination of scientific research documents, whether they are published or not. The documents may come from teaching and research institutions in France or abroad, or from public or private research centers.
L'archive ouverte pluridisciplinaire HAL, est destinée au dépôt et à la diffusion de documents scientifiques de niveau recherche, publiés ou non, émanant des établissements d'enseignement et de recherche français ou étrangers, des laboratoires publics ou privés.

\section{(c)(1)}

Distributed under a Creative Commons Attribution| 4.0 International License 


\title{
DABGPM: A Double Auction Bayesian Game-based Pricing Model in Cloud Market
}

\author{
Shifeng Shang, Jinlei Jiang, Yongwei Wu, Zhenchun Huang \\ Guangwen Yang, Weimin Zheng \\ Department of Computer Science and Technology \\ Tsinghua National Laboratory for Information Science and Technology \\ Tsinghua University, Beijing, 100084, China \\ Email:shangsf@gmail.com \\ \{jjlei, wuyw, huangzc, ygw, zwm-dcs\}@tsinghua.edu.cn
}

\begin{abstract}
Recently IT giants such as Google, Amazon, Microsoft, and IBM are gearing up to be a part of the Cloud and begin to sell their cloud services. However, the current market trading mechanism is inflexible, and the price is not reasonable enough in some situation. Therefore, we first propose a cloud market framework for people to build a uniform and fully competitive cloud market where users can buy resources from different companies and exchange their idle resources in a more flexible way. Then we define a double auction Bayesian Game-based pricing model (DABGPM) for the suggested cloud market and discuss how to develop an optimal pricing strategy for this model. Our work, we think, makes a good example of more flexible and more reasonable cloud resources trading.
\end{abstract}

Keywords: Cloud Computing; Pricing Model; Double Auction; Cloud Market

\section{Introduction}

Cloud computing is becoming a computing buzzword both in industry and academia. Academic efforts include Nimbus [1], Aneka[2][3], OpenNebula [4], and Tsinghua Cloud[5]. In industry, more and more vendors are gearing up and begin to sell their cloud services, for example, Amazon's EC2 and S3 [6], Google's GAE [7], Microsoft Azure [8], Rackspace[9], GoGrid[10], and VPS.net[11], to name but just a few. These services charge users for the resources consumed on a per-use basis.

Currently, most companies adopt a fixed rate pricing strategy, and user can get a great discount through pre-pay method. We argue such a pricing model is not perfect. Firstly, it results in resources waste for applications (e.g., financial analysis) that users only need to run once a month for hours. Secondly, the pre-pay method will potentially make users be locked to certain providers for long with little chance to receive better and cheaper services from other vendors. Thirdly, it even gets expensive to use the fixed rate pricing model in some situation [21]. 
Table 1 shows the services prices of different vendors, where the basic configuration of compute is of $1 \mathrm{~GB}\left(=10^{9}\right.$ bytes) RAM, and 40 GB Disk. We can see that the prices of compute range from $\$ 0.06$ to 0.12 with a maximum difference as much as $\$ 0.06$ per hour for the same resource. Obviously, it would be attractive to establish a uniform and fully competitive cloud computing resources trading market where users can run their applications using resources from different companies as well as exchange unused resources.

Table 1. The cloud services prices of different vendors

\begin{tabular}{|c|c|c|c|c|c|}
\hline Price Type & Amazon & $\begin{array}{c}\text { Windows } \\
\text { Azure }\end{array}$ & Google & GoGrid & Rackspace \\
\hline $\begin{array}{c}\text { Compute CPU } \\
\text { hours }\end{array}$ & $\begin{array}{c}\$ 0.085 / \text { linux } \\
\$ 0.12 / \text { windows }\end{array}$ & $\$ 0.12$ & $\$ 0.10$ & $\$ 0.10$ & $\$ 0.06$ \\
\hline $\begin{array}{c}\text { Storage } \\
\text { GB/month }\end{array}$ & $\$ 0.15$ & $\$ 0.15$ & $\begin{array}{c}\$ 0.15 \\
\text { first } 0.5 \mathrm{~GB} \text { free }\end{array}$ & $\begin{array}{c}\$ 0.15 \\
\text { first 10GB free }\end{array}$ & $\$ 0.15$ \\
\hline $\begin{array}{c}\text { Data Upload } \\
\text { GB }\end{array}$ & $\begin{array}{c}\$ 0.10 \\
\text { Free through } \\
\text { June 30,2010 }\end{array}$ & $\$ 0.10$ & $\$ 0.12$ & $\$$ free & $\$ 0.08$ \\
\hline $\begin{array}{c}\text { Data Download } \\
\text { GB }\end{array}$ & $\begin{array}{c}\$ 0.17 \\
\$ 0.13 \text { if }>10 \mathrm{~TB}\end{array}$ & $\$ 0.15$ & $\$ 0.10$ & $\$ 0.29$ & $\$ 0.22$ \\
\hline
\end{tabular}

The main contributions of this paper are two-fold. Firstly, we propose a cloud market framework for people to build a uniform and fully competitive cloud market where users can trade cloud resources in a more flexible and more effective way. Secondly, we propose the DABGPM model for our cloud market and show how to develop an optimal pricing strategy for this model.

The remainder of this paper is organized as follows. Section 2 is the related work. Section 3 gives an introduction to our global cloud market framework. In Section 4, we define the DABGPM model and discuss how to develop pricing strategies based on it. The last section is the conclusion and future work.

\section{Related Work}

There exist many economy-based resource allocation models in grid research [12], mainly including autonomous pricing mechanism [13], pricing based on the combinatorial auction [14], and pricing based on the commodities market model and load prediction [15]. They applied the auction model, the bargaining model, the combinatorial auction model, and the commodity market model, respectively. But these models usually focus on users without taking providers' price requirements into consideration.

Recently, many research projects such as Tycoon [16] and Shirako [17] have been proposed for trading resource allocations. These projects focus on allocating resources based on economy factor rather than a real market. In other words, they do not take into account the full competition between providers. 
With the rapid advancement of QoS (quality of services) and the establishment of security and interoperability standards for cloud computing, more and more companies began offering cloud resources (e.g., computing, storage, platform and software) and the cloud market is becoming more and more competitive. It is the time to establish a uniform and fully competitive cloud market for trading cloud resources.

\section{Cloud Market Framework}

To facilitate cloud resources trading, we propose a uniform and fully competitive cloud market framework as shown in Fig. 1. There are three main types of participants in this framework, namely the Cloud Market Place (CMP), User Agent (UA), and Cloud Resource Provider (CRP).

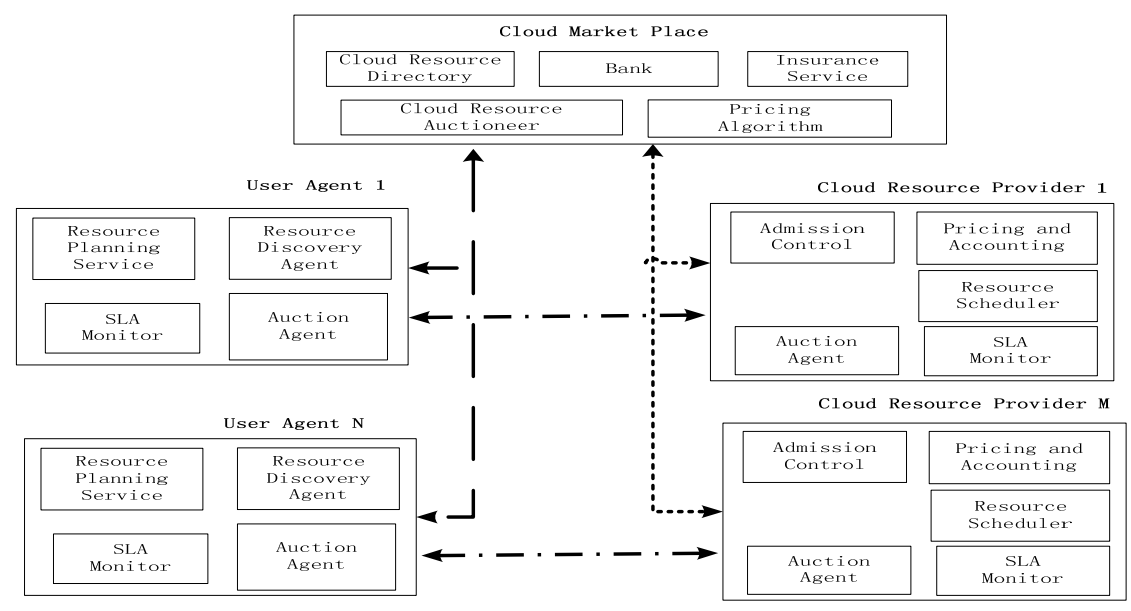

Fig. 1. The Cloud Market Framework

\subsection{Cloud Resource Provider}

Cloud Resource Provider (CRP) is a datacenter that sells its resources to users and profits from it. The resources include computing power, storage space, network bandwidth, etc. CRP has five components, that is, the Auction Agent, the Admission Control, the Resource Scheduler, the Pricing and Accounting, and the SLA Monitor.

- The Auction Agent is responsible for registering resource offers into the Cloud Resource Directory of CMP. It is also auction agent's duty to generate a bid and submit it to the CMP.

- The Admission Control receives the auction result from the auction agent, and decides whether to do the requested tasks or not. 
- The Resource Scheduler is responsible for allocating resources according to the corresponding request. It is also in charge of balancing the supply and demand of cloud resources, providing feedback in terms of economic incentives for both cloud consumers and providers.

- The Pricing and Accounting is responsible for charging users for the resources consumption;

- The responsibility of SLA Monitor is to accept the user's request and guarantee the user-requiring service quality. Cloud providers must consider and meet different QoS requirements of each individual consumer as negotiated in specific SLAs (Service Level Agreements).

\subsection{Cloud Market Place}

CMP is composed of the Cloud Resource Auctioneer, the Pricing Algorithm, the Cloud Resource Directory, the Bank and the Insurance Service.

- The Cloud Resource Auctioneer is responsible for collecting the bids of resources made by the UAs and CRPs. Based on the corresponding bidding information, the auctioneer runs the double auction algorithm to determine the winning UAs and CRPs. It is also in charge of informing the UAs and CRPs who have participated in the auction of the auction results.

- The Pricing Algorithm is responsible for generating specific allocation results and the corresponding pricing information. The price calculated in this component will be sent to all the UAs and CRPs who participate in the trade.

- The Cloud Resource Directory (CRD) allows participants to locate providers or consumers with the right offers. The cloud market place periodically clears bids received from market participants.

- The Bank ensures that financial transactions pertaining to agreements between participants are carried out.

- The Insurance Service provides insurances against a number of events that would harm both providers and users: (1) the cloud resources cannot be delivered to users; (2) the resource availability is interrupted; (3) users do not pay the resources consumed.

\subsection{User Agent}

User agents help users make the appropriate choice of resources and auction types. There are four components within a user agent, that is, the Resource Planning Service, the Resource Discovery Agent, the Auction Agent, and the SLA Monitor.

- The Resource Planning Service (RPS) helps users to determine the most appropriate computing capacity. The service will analyze the existing infrastructure, the deployed applications, and the resource requirements before suggesting a course of action according to users' deadline, budget, and so on. 
- The SLA Monitor uses the result of RPS to form a service quality request and then sends the request to the auction agent. It is also in charge of monitoring the agreed SLAs to guarantee service quality.

- The Resource Discovery Agent is responsible for finding the resources according to users' SLA requirements. It contacts the CRD module of CMP to obtain the list of resources that meet these requirements.

- The Auction Agent is responsible for generating the list of resources returned by the CRD. For each resource available, it makes a bid within the user's SLA requirement and submits it to the CMP.

\section{Pricing Strategies Based on the DABGPM Model}

As more and more IT Giants pave the way for creating a market infrastructure to trade services, a completely open bilateral cloud market will be established in the near future. Since cloud resource providers aim to maximize profit and consumers aim to minimize spending, how to do pricing is important to both sides. Here we proposed the DABGPM pricing model based on $[18,19,20]$ and analyzed pricing strategies with it.

\subsection{The DABGPM Model}

In a fully open and complete competitive global cloud resources exchange market, providers and buyers may not know each others' valuations of cloud resources; it is a strategic game with incomplete information. The economic profit of the two sides (providers and buyers) is related to the strategies of their own and their opponents. Suppose that the total requirement of all users is Y. The providers and the consumers form a double auction, that is, they can decide whether to exchange $Y$ resources. Let $\mathrm{V}_{\mathrm{u}}$ and $\mathrm{V}_{\mathrm{p}}$ be the expected resource price of the user and the provider respectively. Obviously, the provider knows the value of $V_{p}$, but doesn't know the value of $V_{u}$, whereas the consumer knows $\mathrm{V}_{\mathrm{u}}$, but doesn't know $\mathrm{V}_{\mathrm{p}}$. According to the above statements, the DABGPM pricing model involves the following elements:

- a pair of resource provider and consumer, denoted by $\mathrm{N}=(\mathrm{s}, \mathrm{b})$.

- a set of states, denoted by $\Omega=\left\{\left(\mathrm{V}_{\mathrm{p}}, \mathrm{V}_{\mathrm{u}}\right)\right\}$. Indeed, $\Omega$ records the possible quoting prices of provider $s$ and consumer $b$.

- a set of signals, denoted by $\mathrm{T}=\left\{\mathrm{t}_{1}, \mathrm{t}_{2}, \ldots\right\}$. Each signal indicates a resource quoting action.

- a signal function $\tau_{\mathrm{i}}(\mathrm{t} \rightarrow \Omega)$, which means signals will trigger state change.

- a probability function that describes the possibility of each state in $\Omega$.

Assume that $V_{p}$ and $V_{u}$ are uniformly distributed on [0,1], and the provider and the user bids and offers at the same time. Obviously, we have $\mathrm{P}_{\mathrm{s}} \in[0,1]$ and $\mathrm{P}_{\mathrm{b}} \in[0,1]$. If $\mathrm{P}_{\mathrm{s}} \leqslant \mathrm{P}_{\mathrm{b}}$, two sides will make a deal at price $\mathrm{P}=\mathrm{kP}_{\mathrm{s}}+(1-\mathrm{k}) \mathrm{P}_{\mathrm{b}}$; Otherwise, the deal will not happen. The payoff function of resource provider is as follows: 


$$
\mathrm{U}_{\mathrm{s}}=\left\{\begin{array}{cl}
\mathrm{kp}_{\mathrm{s}}+(1-\mathrm{k}) \mathrm{p}_{\mathrm{b}}-V_{p} & \text { if } \mathrm{p}_{\mathrm{s}} \leq \mathrm{p}_{b} \\
0 & \text { if } \mathrm{p}_{\mathrm{s}}>\mathrm{p}_{b}
\end{array}\right.
$$

The payoff function of user $b$ is as follows:

$$
\mathrm{U}_{\mathrm{b}}=\left\{\begin{array}{cl}
V_{u}-\left(\mathrm{kp}_{\mathrm{s}}+(1-\mathrm{k}) \mathrm{p}_{\mathrm{b}}\right) & \text { if } \mathrm{p}_{\mathrm{s}} \leq \mathrm{p}_{b} \\
0 & \text { if } \mathrm{p}_{\mathrm{s}}>\mathrm{p}_{b}
\end{array}\right.
$$

\subsection{The Solution of DABGPM Model}

According to the double auction process and rules, $\mathrm{V}_{\mathrm{p}}$ and $\mathrm{V}_{\mathrm{u}}$ is independent and uniformly distributed on $[0,1]$, the selling price of provider $s$ is $\mathrm{P}_{\mathrm{s}}\left(\mathrm{V}_{\mathrm{p}}\right)$; the bidding price of buyer $\mathrm{b}$ is $\mathrm{P}_{\mathrm{b}}\left(\mathrm{V}_{\mathrm{u}}\right)$, the strategy $\left(\mathrm{p}_{\mathrm{s}}^{*}\left(\mathrm{~V}_{p}\right), \mathrm{p}_{\mathrm{b}}^{*}\left(\mathrm{~V}_{u}\right)\right)$ is a optimal strategy if and only if the following two conditions are met.

(1) $\mathrm{p}_{\mathrm{s}}^{*}\left(\mathrm{~V}_{p}\right)$ is one solution to the optimization question:

$$
\max _{P_{s}}\left[\mathrm{k}\left(\mathrm{p}_{\mathrm{s}}+\mathrm{E}\left[\left(\mathrm{p}_{\mathrm{b}}\left(\mathrm{V}_{u}\right) \mid\left(\mathrm{p}_{\mathrm{b}}\left(\mathrm{V}_{u}\right) \geq \mathrm{p}_{\mathrm{s}}\right)\right]\right)-c\right] \mathrm{P}\left\{\mathrm{p}_{\mathrm{b}}\left(V_{u}\right) \geq \mathrm{p}_{\mathrm{s}}\right\}\right.
$$

$\left.\mathrm{E}\left[\left(\mathrm{p}_{\mathrm{b}}\left(\mathrm{V}_{\mathrm{u}}\right) \mid \mathrm{p}_{\mathrm{b}}\left(\mathrm{V}_{\mathrm{u}}\right)\right] \geqslant \mathrm{p}_{\mathrm{s}}\right)\right]$ is the expected price when the providers' selling price is lower than consumers' bidding price.

(2) $\mathrm{p}_{\mathrm{b}}^{*}\left(\mathrm{~V}_{u}\right)$ is one solution to the optimization question:

$$
\max _{P_{b}}\left[\mathrm{~V}_{u}-\mathrm{kp}_{\mathrm{b}}-\mathrm{kE}\left[\mathrm{p}_{\mathrm{s}}\left(\mathrm{V}_{p}\right) \mid \mathrm{p}_{\mathrm{b}} \geq \mathrm{p}_{\mathrm{s}}\left(\mathrm{V}_{p}\right)\right]\right] P\left\{p_{b} \geq p_{s}\left(\mathrm{~V}_{p}\right)\right\}
$$

$\mathrm{E}\left[\left(\mathrm{p}_{\mathrm{s}}\left(\mathrm{V}_{p}\right) \mathrm{p}_{\mathrm{b}} \geq \mathrm{p}_{\mathrm{s}}\left(\mathrm{V}_{p}\right)\right)\right.$ is the expected price when the providers' selling price is lower than consumers' bidding price, $\mathrm{p}_{\mathrm{s}}^{*}\left(\mathrm{~V}_{p}\right)$ and $\mathrm{p}_{\mathrm{b}}^{*}\left(\mathrm{~V}_{u}\right)$ are the optimal strategy of provider $\mathrm{s}$ and consumer $\mathrm{b}$ respectively.

Assuming the provider and consumer are all adopting a linear bidding pricing strategy, the solution of DABGPM is below:

$$
\left\{\begin{array}{l}
\mathrm{p}_{\mathrm{s}}\left(\mathrm{V}_{p}\right)=\alpha_{\mathrm{s}}+\beta_{\mathrm{s}} \mathrm{V}_{p} \\
\mathrm{p}_{\mathrm{b}}\left(\mathrm{V}_{u}\right)=\alpha_{\mathrm{b}}+\beta_{\mathrm{b}} \mathrm{V}_{u}
\end{array}\right.
$$

$\mathrm{V}_{u}$ is defined as of the uniform distribution, hence, $\mathrm{p}_{\mathrm{b}}$ is also uniformly distributed on the interval $\left[\alpha_{b}, \alpha_{b}+\beta_{b}\right]$, therefore

$$
\begin{array}{r}
\mathrm{P}\left\{\mathrm{p}_{\mathrm{b}}\left(\mathrm{V}_{u}\right) \geq \mathrm{p}_{\mathrm{s}}\right\}=\mathrm{P}\left\{\alpha_{\mathrm{b}}+\beta_{\mathrm{b}} \mathrm{V}_{u} \geq \mathrm{p}_{\mathrm{s}}\right\}=\frac{\alpha_{\mathrm{b}}+\beta_{\mathrm{b}}-\mathrm{p}_{\mathrm{s}}}{\beta_{\mathrm{b}}} \\
\mathrm{E}\left[\mathrm{p}_{\mathrm{b}}\left(\mathrm{V}_{u}\right) \mid \mathrm{p}_{\mathrm{b}}\left(\mathrm{V}_{u}\right) \geq \mathrm{p}_{\mathrm{s}}\right]=\frac{\frac{1}{\beta_{\mathrm{b}} \int_{\mathrm{p}_{\mathrm{s}}}^{\alpha_{\mathrm{b}}+\beta_{\mathrm{b}}} \mathrm{xdx}}}{\mathrm{P}\left\{\mathrm{p}_{\mathrm{b}}\left(\mathrm{V}_{u}\right) \geq \mathrm{p}_{\mathrm{s}}\right\}}=\frac{1}{2}\left(\mathrm{p}_{\mathrm{s}}+\alpha_{\mathrm{b}}+\beta_{\mathrm{b}}\right)
\end{array}
$$




$$
\max _{P_{s}}\left[k p_{s}+\frac{k-1}{2}\left(p_{s}+\alpha_{b}+\beta_{b}\right)-\mathrm{V}_{p}\right] \cdot \frac{\alpha_{b}+\beta_{b}-p_{s}}{\beta_{b}}
$$

Applying its first-order condition, we get:

$$
\mathrm{p}_{\mathrm{s}}=\frac{\mathrm{k}}{\mathrm{k}+1}\left(\alpha_{\mathrm{s}}+\beta_{\mathrm{s}}\right)+\frac{1}{\mathrm{k}+1} \mathrm{~V}_{p}
$$

Thus it can be seen, if consumer $b$ adopting a linear strategy, the optimal response of cloud resource provider is also linear. As the same, because $\mathrm{V}_{p}$ is of uniform distribution, hence, $\mathrm{p}_{s}$ is also of uniform distribution on the interval $\left[\alpha_{s}, \alpha_{s}+\beta_{s}\right]$, therefore:

$$
\begin{gathered}
\mathrm{P}\left\{\mathrm{p}_{\mathrm{b}} \geq \mathrm{p}_{\mathrm{s}}\left(\mathrm{V}_{p}\right)\right\}=\mathrm{P}\left\{\mathrm{p}_{\mathrm{b}} \geq \alpha_{\mathrm{s}}+\beta_{\mathrm{s}} \mathrm{V}_{p}\right\}=\frac{\mathrm{p}_{\mathrm{b}}-\alpha_{\mathrm{b}}}{\beta_{\mathrm{s}}} \\
\mathrm{E}\left[\mathrm{p}_{\mathrm{s}}\left(\mathrm{V}_{p}\right) \mid \mathrm{p}_{\mathrm{b}}\left(\mathrm{V}_{u}\right) \geq \mathrm{p}_{\mathrm{b}} \geq \mathrm{p}_{\mathrm{s}}\left(\mathrm{V}_{p}\right)\right]=\frac{\frac{1}{\beta_{\mathrm{s}}} \int_{\alpha_{\mathrm{s}}}^{\mathrm{p}_{\mathrm{b}}} \mathrm{x} d \mathrm{x}}{\mathrm{P}\left\{\mathrm{p}_{\mathrm{b}} \geq \mathrm{p}_{\mathrm{s}}\left(\mathrm{V}_{p}\right)\right\}}=\frac{1}{2}\left(\mathrm{p}_{\mathrm{b}}+\alpha_{\mathrm{s}}\right)
\end{gathered}
$$

Inserting equation (10) and (11) into the effective function of buyer, we can obtain:

$$
\max _{P_{b}}\left[\mathrm{~V}_{u}-\left((1-k) p_{b}+\frac{k}{2}\left(p_{b}+\alpha_{s}\right)\right)\right] \cdot \frac{p_{b}-\alpha_{b}}{\beta_{s}}
$$

Applying its first-order condition, we get:

$$
p_{b}=\frac{k}{1+k} a_{s}+\frac{1}{1+k} \mathrm{~V}_{u}
$$

Synthesizing equation (5), (9) and (13), we can obtain a pricing solution between cloud resource providers and buyers:

$$
\left\{\begin{array}{l}
p_{s}\left(V_{p}\right)=\frac{k}{2 k+1}+\frac{1}{k+1} V_{p} \\
p_{b}\left(V_{u}\right)=\frac{k^{2}}{(1+k)(1+2 k)}+\frac{1}{k+1} V_{u}
\end{array} k \in[0,1]\right.
$$

\subsection{Pricing strategy analysis}

The Formula (14) has given an equilibrium pricing strategy between cloud providers and consumers; we will analyze the characteristics of it. For the sake of simplicity, we assume that $k=0.5$ and thus the formula (14) changes into (15): 


$$
\left\{\begin{array}{l}
p_{s}\left(V_{p}\right)=\frac{1}{4}+\frac{2}{3} V_{p} \\
p_{b}\left(V_{u}\right)=\frac{1}{12}+\frac{2}{3} V_{u}
\end{array}\right.
$$

(1)Based on the linear equilibrium strategy, the highest bidding price of consumer is $\mathrm{p}_{\mathrm{b}}(1)=0.75$, and the lowest price of provider is $p_{s}(0)=0.25$;

(2)If $V_{p}>0.75$, the selling price of provider $p_{s}\left(V_{p}\right)=0.25+2 / 3 V_{p}$ is lower than the real cost. Even if it is higher than the highest bidding price $\mathrm{p}_{\mathrm{b}}(1)=0.75$, the trade will not happen.

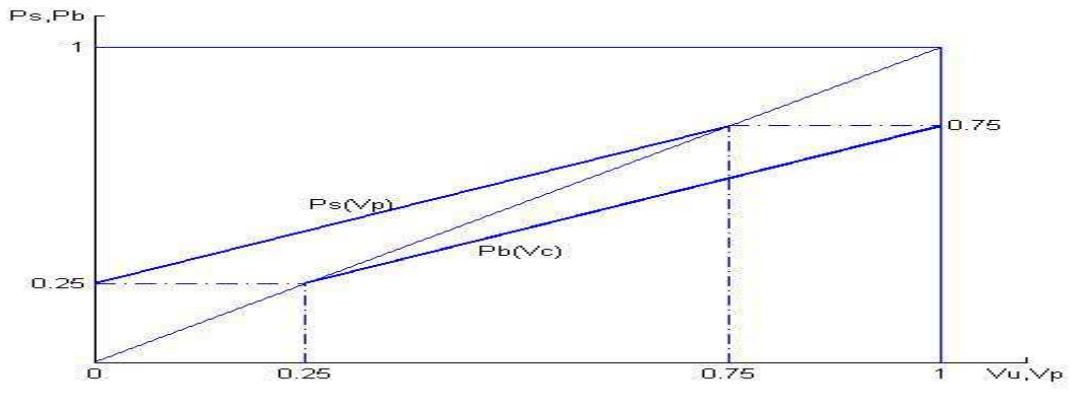

Fig. 2. The Solution of DABGPM Model

(3)When $V_{u}<0.25$, although the bidding price is higher than the cost, it is lower than the lowest selling price, $\mathrm{p}_{\mathrm{s}}(0)=0.25$, the trade will not happen either. This can be seen from Fig. 2. The two lines $p_{s}\left(V_{p}\right)=0.25+2 / 3 V_{p}$ and $\mathrm{p}_{\mathrm{b}}\left(V_{u}\right)=1 / 12+(2 / 3) V_{u}$ indicate the optimal pricing strategy of provider and consumer is the bold line in Fig. 2.

(4)From the above analysis, we can conclude that $p_{s}\left(V_{p}\right)=0.25+2 / 3 V_{p}$ and $\mathrm{p}_{\mathrm{b}}\left(V_{u}\right)=1 / 12+(2 / 3) V_{u}$ is the optimal pricing strategy of provider and consumer respectively. For example, when the cost of provider is 0.3 , the optimal price is 0.45 , when the valuation of buyer $\mathrm{v}$ is 1.0 , the optimal price is 0.75 .

\section{Conclusion}

With the development of cloud technology, there will be more users and companies renting hardware and/or software resources from the cloud instead of buying and maintaining by themselves. As more and more IT giants invest into the technology, cloud computing has evolved into a big piece of cake. It is a trend that a uniform and complete competitive cloud resources market will emerge in the near future. For such a market, the trading strategy and reasonable price is important. To facilitate such a 
market, we proposed a complete competitive cloud market framework and a double auction Bayesian game-based pricing model and discussed pricing strategies based on this model. We think the work reported here makes a good example of more flexible and more reasonable cloud resources trading and would promote the applications of cloud computing.

\section{Acknowledgement}

This Work is supported by Natural Science Foundation of China (60803121, 60773145, 60911130371, 90812001, 60963005), National High-Tech R\&D (863) Program of China (2009AA01A130, 2006AA01A101, 2006AA01A108, 2006AA01A111, 2006AA01A117).

\section{References}

1. http://www.nimbusproject.org/

2. Buyya, R.: Market-Oriented Cloud Computing: Vision, Hype, and Reality of Delivering Computing as the 5th Utility. : Proceedings of the 2009 9th IEEE/ACM International Symposium on Cluster Computing and the Grid. IEEE Computer Society (2009)

3. Chu, X., Nadiminti, K., Jin, C., Venugopal, S., Buyya, R.: Aneka: Next-Generation Enterprise Grid Platform for e-Science and e-Business Applications. : Proceedings of the Third IEEE International Conference on e-Science and Grid Computing. IEEE Computer Society (2007) 151-159

4. OpenNebula Project. http://www.opennebula.org/

5. Zheng, W. M.: An Introduction to Tsinghua Cloud. Science in China Series F: Information Science, vol. 53, no. 5(2010)

6. Amazon Elastic Compute Cloud (EC2), http://aws.amazon.com/ec2/

7. http://www.microsoft.com/windowsazure/

8. Google App Engine,http://appengine.google.com

9. http://www.rackspace.com/index.php

10. http://www.gogrid.com/index.v2.php

11.http://www.vps.net/

12.Buyya, R., Abramson, D., and Venugopal, S.: The Grid Economy. Proceedings of the IEEE, 93(3): 698-714, IEEE Press, USA(2005)

13.Jin, Y., Shoubao, Y., Maosheng, L., Qianfei, F.: An Autonomous Pricing Strategy toward Market Economy in Computational Grids. : Proceedings of the International Conference on Information Technology: Coding and Computing (ITCC'05) - Volume II - Volume 02. 793794. IEEE Computer Society (2005)

14.Schwind, M., Gujo, O., Stockheim, T.: Dynamic Resource Prices in a Combinatorial Grid System. : Proceedings of the The 8th IEEE International Conference on E-Commerce Technology and The 3rd IEEE International Conference on Enterprise Computing, ECommerce, and E-Services. IEEE Computer Society (2006)

15.Zhao, X., Xu, L., Wang, B.: A Dynamic Price Model with Demand Prediction and Task Classification in Grid.:Proceedings of the Sixth International Conference on Grid and Cooperative Computing. IEEE Computer Society (2007) 775-782 
16.Lai, K., Rasmusson, L., Adar, E., Zhang, L., Huberman, B.A.: Tycoon: An implementation of a distributed, market-based resource allocation system. Multiagent Grid Syst. Vol.1. 169$182(2005)$

17.Irwin, D., Chase, J., Grit, L., Yumerefendi, A., Becker, D., Yocum, K.G.: Sharing networked resources with brokered leases.:Proceedings of the annual conference on USENIX '06 Annual Technical Conference. USENIX Association, Boston, MA (2006)

18.Ren, Yu.L., Zou, X.Y.: Bidding game model of a power generation company based on firstprice sealed auction, Journal of Systems Engineering, Vol. 18, No. 3, pp. 248-254(2003)

19.FANG D.B., WANG, X.J., ZHANG, Y.X., LIU, K., WANG, P., ZHU Z.Y.: A Double auction Bayesian model with supplier and demander in open bilateral electricity market. Power System Technology(in Chinese), vol.27 No.12(2003).

20.Gibbons, R.: A Primer in Game Theory. Pearson Higher Education(1992)

21.Wilkening, J., Wilke, A., Desai, N., Meyer, F.: Using clouds for metagenomics: A case study.:Cluster Computing and Workshops, 2009. CLUSTER '09. IEEE International Conference on (2009) 